\title{
Digestive Manifestation in COVID-19 Patient Complicated by Occlusive Syndrome Admitted to Intensive Care in a Case
}

\author{
Abdoulaye Touré1 ${ }^{*}$, Amadou Yalla Camara², Joseph Donamou ${ }^{2}$, Boubacar Atigou Dramé1, \\ Fofana Naby ${ }^{3}$, Oularé Ibrahima ${ }^{3}$, Camara M'mah Lamine², Bangoura Almamy', \\ Camara Mariama Mohamed1, Emile Camara ${ }^{3}$, Godwe Justin Naibe ${ }^{1}$
}

${ }^{1}$ Anesthesia-Intensive Care Unit at the National Ignace Deen Hospital, Conakry, Guinea

${ }^{2}$ Anesthesia-Intensive Care Unit at the Donka National Hospital, Conakry, Guinea

${ }^{3}$ General Surgery Department of the National Ignace Deen Hospital, Conakry, Guinea

Email: ^atfmamad@gmail.com

How to cite this paper: Touré, A., Camara, A.Y., Donamou, J., Dramé, B.A., Naby, F., Ibrahima, O., Lamine, C.M., Almamy, B., Mohamed, C.M., Camara, E. and Naibe, G.J. (2020) Digestive Manifestation in COVID-19 Patient Complicated by Occlusive Syndrome Admitted to Intensive Care in a Case. Open Journal of Emergency Medicine, 8, 110-117. https://doi.org/10.4236/ojem.2020.84012

Received: October 29, 2020

Accepted: December 20, 2020

Published: December 23, 2020

Copyright $\odot 2020$ by author(s) and Scientific Research Publishing Inc. This work is licensed under the Creative Commons Attribution International License (CC BY 4.0).

http://creativecommons.org/licenses/by/4.0/

(c) $\underset{\mathrm{By}}{\mathrm{i}}$ Open Access

\begin{abstract}
We report the case of a 39-year-old patient with a history of chronic gastritis, functional colopathy and appendectomy, referred by another public institution for severe abdominal pain. He had been admitted 6 days previously for nausea, vomiting, diarrhea, fever, asthenia since the onset of dyspnea with $89 \%$ desaturation in ambient air and a dry cough. A diagnosis of gastroenteritis was made and treated without success. The appearance of abdominal distension and bloating motivated his transfer to the CTPI where the rRT-PCR was carried out positive and an X-ray of the abdomen without preparation which had demonstrated a significant aerocoly with agglutination of handle. Surgical management under general anesthesia found a clean cavity after coeliotomy, multiple intestino-intestinal, intestino-parietal and omentum-parietal adhesions. The gesture consisted of an adhesiolysis, omentectomy. The postoperative follow-up was favorable with resumption of transit on D5 postoperative. Put under the COVID-19 treatment protocol, the rRT-PCR was negative on D13, output on D14 and removal of the D19 files without postoperative complications.
\end{abstract}

\section{Keywords}

Resuscitation, COVID-19, Digestive Manifestation, Occlusive Syndrome, Donka

\section{Introduction}

Coronavirus-2019 (COVID-19) disease caused by coronavirus 2 (SARS-CoV-2) 
infection due to severe acute respiratory syndrome is a global health concern. Severe COVID-19 can lead to multi-organ failure and may be associated with high mortality. Age, severity of infection, and comorbidity are important predictors of poor outcomes from COVID-19 [1] [2]. Coronaviruses are a common source of upper respiratory tract, gastrointestinal and central nervous system infections in humans and other mammals [3]. The first patient reported with 2019 coronavirus disease (COVID-19) in the United States reported gastrointestinal (GI) symptoms of loose stools and abdominal discomfort. The patient's stool and respiratory tract samples were tested positive for SARS-CoV-2 by real-time reverse transcription polymerase chain reaction (RT-PCR) [4].

\section{Case Presentation}

A 39-year-old male patient with a history of gastritis, functional colopathy and appendectomy, had been referred from another facility for abdominal pain. The patient had been admitted there 6 days previously for nausea, vomiting and febrile diarrhea. A diagnosis of acute gastroenteritis plus malaria was made and the patient was treated with metronidazole $500 \mathrm{mg}$ injection three times a day combined with ceftriaxone $2 \mathrm{~g}$ as a single dose, paracetamol injection $1 \mathrm{~g}$ three times a day and artesunate injection. Despite this treatment, no improvement was noted and the patient became increasingly asthenic with the onset of abdominal distension, which prompted transfer to the epidemiological treatment center of the Donka National Hospital (CTPI). The physical examination on admission would have objective a patient with a poor general condition, asthenic, respiratory disorder (a dyspnea type of polypnea associated with a dry cough.) A pulse at 67 pulses/min, desaturation at $89 \%$ in air ambient, arterial pressure $110 / 71 \mathrm{mmHg}$, respiratory rate $26 \mathrm{cycles} / \mathrm{min}$ and temperature $39.4^{\circ} \mathrm{C}$.

The hepato-digestive examination showed a very distended, painful, tender abdomen as a whole associated with abdominal bloating, dullness on percussion, loss of materials and gas. The intensive care unit consisted of taking two venous routes, fitting a nasogastric tube and urinary catheter, hydration with Ringer Lactate, oxygen therapy, analgesia (paracetamol). A nasopharyngeal swab by reverse transcription polymerase chain reaction (rRT-PCR) was taken and tested positive. An x-ray of the abdomen without preparation (ASP) was practical in emergency and showed significant aerocoly with agglutination of the loop, not hydro-aeric level, or clear mechanical occlusion (Figure 1). Biologically, there was hyponatremia at $132 \mathrm{mmol} / \mathrm{L}$, hypochloremia at 89.4 , hypocalcemia at 1.19 $\mathrm{mmol} / \mathrm{L}$, serum creatinine at $13.9 \mathrm{mg} / \mathrm{L}$, urea at $0.22 \mathrm{~g} / \mathrm{L}, \mathrm{D}$-dimer at 8359.05 $\mathrm{ng} / \mathrm{L}, \mathrm{CRP}$ at $159 \mathrm{mg} / \mathrm{L}$, Hemoglobin at $14.10 \mathrm{~g} / \mathrm{dl}$, Leukocytes at $6.19 \mathrm{103} / \mathrm{mm}^{3}$, Platelet at $150 \mathrm{G} / \mathrm{L}$, prothrombin level at $70 \%$, activated partial thromboplastin time at 37.3 seconds, blood group $\mathrm{O}, \mathrm{Rh}$ positive.

The notice of visceral surgery to ask had given an indication for surgery. Surgical management of the patient was performed in the block 10 hours after admission. It was performed under general anesthesia. Rapid sequence induction 


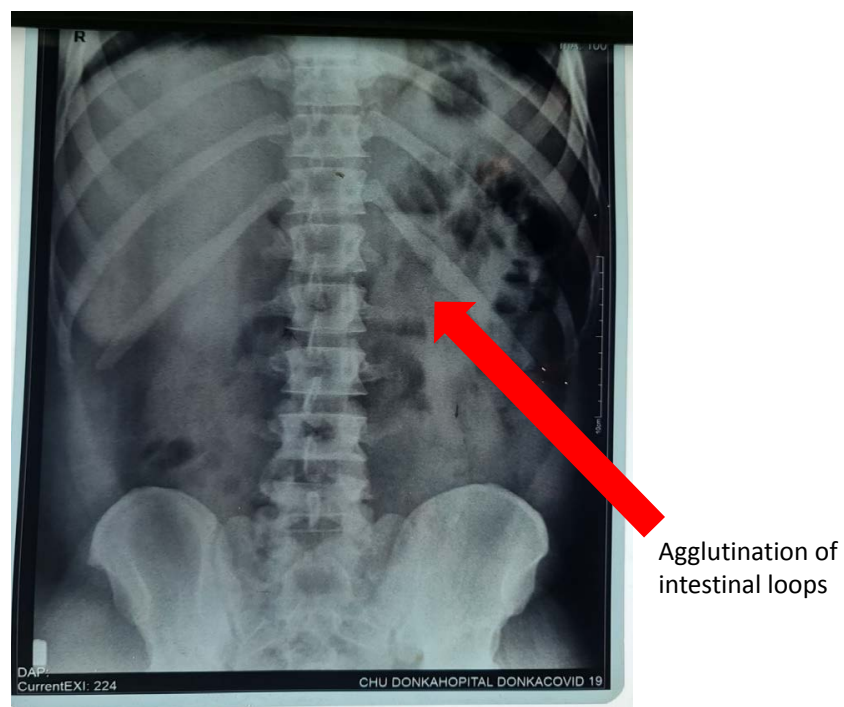

Figure 1. Roentgenogram of the abdomen without preparation showing agglutination of the slender loops.

with Rocuronium administration and Sellick maneuver was performed. The hypnotic used was propofol. Intraoperatively analgesia was provided by fentanyl as an opioid and maintenance by halothane as a halogen. Mechanical ventilation with an anesthesia ventilator was performed. The surgery lasted $130 \mathrm{~min}$. At the coeliotomy, the exploration revealed a clean cavity, multiple intestinal-intestinal, intestino-parietal and omentum-parietal adhesions. The procedure consisted of adhesiolysis, omentectomy from wall closure plan by plan plus dressing. Extubation was done in intensive care 3 hours after the patient was transferred to intensive care. The postoperative follow-up was favorable with resumption of transit on D5 postoperative. The patient was put under the COVID-19 treatment protocol consisting of hydroxychloroquine (200 $\mathrm{mg} 1 \mathrm{cpx} 3 /$ day for 10 days) and azithromycin (500 mg 1cp/day1 then $250 \mathrm{mg} /$ day for 04 days), zinc $20 \mathrm{mg} /$ day for 10 days and Vitamin C $1000 \mathrm{mg}$ effervescent tablet $1 \mathrm{tab} /$ day in the morning, dexamethasone $4 \mathrm{mg}$ (20 mg IV for 5 days then $10 \mathrm{mg}$ for 5 days and $4 \mathrm{mg}$ for 4 days after stopping), lopinavir + ritonavir $200 \mathrm{mg} / 50 \mathrm{mg}(1$ tablet $\times 2 /$ day for 10 days), Enoxaparin sodium $100 \mathrm{IU} / \mathrm{kg} / 12$ hours.

The evolution was favorable on D13, marked by the improvement of the biological data and the negativation of the rRT-PCR at the control, justifying the patient's home discharge on D14 with weekly outpatient consultation. On D19 complete removal of the files.

\section{Discussion}

SARS-CoV-2 is responsible for a polymorphic digestive symptomatology that may precede the onset of respiratory symptoms. This is the case we have described where the initial care begins only in the complications phase. In the cohort of 552 Chinese hospitals comprising 1099 patients published in the New England Journal of Medicine, the authors observed nausea or vomiting in 5\% of 
cases and diarrhea in $3.8 \%$ of cases [5]. More recent cohorts suggest that diarrhea can be observed in $2 \%$ to $10 \%$ of cases, or even up to $39 \%$ in a cohort of 140 patients, while nausea or vomiting was reported in $1 \%$ to $17 \%$ of cases [6] [7]. This is the case with our patient where the symptoms were gastroenteritis. In a Chinese retrospective series of 1141 confirmed cases of COVID-19, 16\% of patients had isolated digestive symptoms [8]. It was diarrhea in $37 \%$ of cases and abdominal pain in $25 \%$ of cases. In another study of 204 patients, $51 \%$ had digestive impairment, including diarrhea in $34 \%$ of cases [9]. Patients with digestive symptoms had a longer hospital stay compared to those without digestive symptoms. Several authors have also observed a correlation between the severity of respiratory involvement and the intensity of digestive symptoms. These elements are confirmed by a study of 651 patients, of whom $11.4 \%$ had at least one digestive symptom. Patients with digestive symptoms had more severe disease ( $\mathrm{p}$ $<0.001$ ) [10]. In our case, the first symptoms were digestive then the respiratory symptoms. On the mechanisms of digestive involvement, evidence of involvement of the digestive system in patients with COVID-19 was first reported by a group in China [11]. Emerging data has shown that the gastrointestinal tract and liver may also represent target organs of severe acute respiratory syndrome coronavirus 2 (SARS-CoV-2) based on the findings that the converting enzyme angiotensin 2 (ACE2), the major receptor for SARS -CoV-2, is expressed in the gastrointestinal tract as well as in liver cells [12]. The detection of SARS-CoV-2 viral RNA in patient stools and the potential for fecal-oral transmission have raised great concerns and could pose a challenge for the control and prevention of COVID-19 [4] [13] [14]. The major challenge was to determine the etiology of this occlusive syndrome because the treatment approach depends on it. In our case, the epidemiological argument led us to first mention the inflammatory reaction due to COVID-19 as the etiology.

SARS-CoV-2 could also be responsible for direct intestinal damage via the inflammatory response. Several studies have also shown the presence of the virus' genetic material in the stool (up to 53\% of patients analyzed [6] [7]. Wong et al. as well as Tian Y et al. had shown that it is possible that the presence of coronavirus disrupts the intestinal microbiota [6] [7]. For our patient, the worsening of digestive symptoms could be due to a significant inflammatory response. The initial management of such patients must not endure any delay and the diagnostic and therapeutic approach must be extremely rigorous.

The most reported digestive comorbidities included chronic hepatitis or cirrhosis of the liver and peptic ulcer disease. In our case, the patient had a functional colopathy caused by chronic constipation. Several case studies have reported that gastrointestinal symptoms were the first symptoms of COVID-19 [8] [15]-[21]. Early COVID-19-induced diarrhea was first reported in a patient with COVID-19 in China, and then confirmed in patients in Singapore and Japan [22] [23] [24]. The overall estimate of gastrointestinal symptoms as symptomatic was $10 \%$ (95\% CI 04/19;03/23 range; $\mathrm{I}=97 \%)$. Patients with gastrointestinal 
symptoms had a longer time from disease onset to hospitalization (standardized mean difference $[\mathrm{SMD}] 2 \cdot 85$ [95\% CI $0 \cdot 22-5 \cdot 48] ; \mathrm{p}=0.030 ; \mathrm{I}=73 \%$ ).

During the COVID-19 pandemic, some patients initially presented with abdominal symptoms without fever or respiratory manifestations [22]. In a large multicenter study of 204 patients with COVID-19 in three hospitals heavily affected during the initial epidemic in China, 103 (50\%) patients presented digestive symptoms as the main complaint [9]. Six (3\%) patients presented with digestive symptoms but no respiratory symptoms [8]. In a large series of cases, (n $=1141)$ patients admitted to hospital with COVID-19, 183 (16\%) had gastrointestinal symptoms only. Wang and colleagues also found that approximately $10 \%$ of patients initially presented with diarrhea and nausea 1 to 2 days before the onset of fever and dyspnea [25].

A link between gastrointestinal involvement and the severity of COVID-19 disease has been proposed. In a multicentre study, Pan et al studied the prevalence and outcome of patients with COVID-19 with digestive symptoms. In 99 patients who presented digestive symptoms as the main complaint, a longer time between onset and admission was observed compared to patients without digestive symptoms (9.0 days vs 7.3 days). As the severity of the disease increased, the digestive symptoms became more numerous. Patients without digestive symptoms were more likely to be cured and discharged than patients with digestive symptoms (60\% vs. 34\%) [9]. This finding was consistent with the study by Wang and colleagues, who found that patients admitted to the ICU were more likely to suffer from abdominal pain and loss of appetite than non-resuscitated patients [25].

The prognosis for patients with COVID-19 with gastrointestinal symptoms is still largely unknown. The studies implied that patients with COVID-19 with digestive symptoms may have a worse clinical outcome than those without digestive symptoms, highlighting the importance of including symptoms such as diarrhea to diagnose COVID-19 early [9] [10].

In addition, patients with COVID-19 with gastrointestinal symptoms had significantly higher rates of acute respiratory distress syndrome complications and liver damage than those without these symptoms [10]. This is the case with our patient where digestive symptoms preceded respiratory involvement. Pan et al also showed that as the severity of the disease increased, digestive symptoms became more pronounced [9].

\section{Conclusion}

This observation clearly shows that the digestive manifestations of COVID-19 made of abdominal pain, nausea, vomiting and diarrhea can precede the respiratory symptoms of COVID-19; ignoring these manifestations can lead to formidable complications. The diagnosis of COVID-19 must always be made in all patients with these digestive manifestations in case of doubt; an rRT-PCR sample must be taken without delay. 


\section{Authors' Contributions}

All authors have read and approved the final version of the manuscript.

\section{NB}

The free and informed consent was requested from the patient for the surgical intervention and the scientific publication of the case as well as the use of the images.

\section{Conflicts of Interest}

The authors declare no conflicts of interest regarding the publication of this paper.

\section{References}

[1] Yang, J., Zheng, Y.A., Gou, X.I., Pu, K., Chen, Z.F., Guo, Q.H., et al. (2020) Prevalence of Comorbidities and Its Effects in Patients with SARS-CoV-2: Systematic Review and Meta-Analysis. International Journal of Infectious Diseases, 94, 91-95. https://doi.org/10.1016/j.ijid.2020.03.017

[2] Chen, Y., Luo, R., Wang, K., Zhang, M., Wang, Z.X., Dong, L., et al. (2020) Kidney Disease Is Associated with In-Hospital Death of Patients with COVID-19. Kidney International, 97, 829-838. https://doi.org/10.1016/j.kint.2020.03.005

[3] Perlman, S. and Netland, J. (2009) Coronaviruses Post-SRAS: Update on Replication and Pathogenesis. Nature Reviews Microbiology, 7, 439-450. https://doi.org/10.1038/nrmicro2147

[4] Holshue, M.L., DeBolt, C., Lindquist, S., Lofy, K.H., Wiesman, J., Bruce, H., et al. (2020) First Case of the 2019 Novel Coronavirus in the United States. The New England Journal of Medicine, 382, 929-936. https://doi.org/10.1056/NEJMoa2001191

[5] Guan, W.J., Ni, Z.Y., Hu, Y., Liang, W.-H., Ou, C.Q., He, J.-X., Liu, L., et al. (2020) Clinical Characteristics of Coronavirus Disease 2019 in China. The New England Journal of Medicine, NEJMoa2002032. https://dx.doi.org/10.1056\%2FNEJMoa2002032 https://www.ncbi.nlm.nih.gov/pmc/articles/PMC7092819/

[6] Wong, S.H., Lui, R.N. and Sung, J.J. (2020) Covid-19 and the Digestive System: Covid-19 and the Digestive System. Journal of Gastroenterology and Hepatology, 35, 744-748. https://doi.org/10.1111/jgh.15047

[7] Tian, Y., Rong, L., Nian, W.D. and He, Y. (2020) Review Article: Gastrointestinal Features in COVID-19 and the Possibility of Faecal Transmission. Alimentary Pharmacology \& Therapeutics, 51, 843-851. https://doi.org/10.1111/apt.15731

[8] Luo, S., Zhang, X., Xu, H. (2020) Don't Overlook Digestive Symptoms in Patients with 2019 Novel Coronavirus Disease (COVID-19). Clinical Gastroenterology and Hepatology, 18, 1636-1637. https://linkinghub.elsevier.com/retrieve/pii/S1542356520304018

[9] Pan, L., Mu, M., Yang, P.C., Sun, Y., Wang, R.S., Yan, J.H., et al. (2020) Clinical Characteristics of COVID-19 Patients with Digestive Symptoms in Hubei, China: A Descriptive, Cross-Sectional, Multicenter Study. The American Journal of Gastroenterology, 115, 766-773. 
https://doi.org/10.14309/ajg.0000000000000620

https://journals.lww.com/ajg/Documents/COVID_Digestive_Symptoms_AJG_Prep roof.pdf

[10] Jin, X., Lian, J.-S., Hu, J.-H., Gao, J.G., Zheng, L., Zhang, Y.M., et al. (2020) Epidemiological, Clinical and Virological Characteristics of 74 Cases of Coronavirus-Infected Disease 2019 (COVID-19) with Gastrointestinal Symptoms. Gut, 69, 1002-1009. http://dx.doi.org/10.1136/gutjnl-2020-320926

[11] Xiao, F., Tang, M.W., Zheng, X.B., Li, X.F. and Shan, H. (2020) Evidence of Gastrointestinal SARS-CoV-2 Infection. Gastroenterology, 158, 1831-1833.E3. https://doi.org/10.1053/j.gastro.2020.02.055

[12] Qi, F.R., Qian, S., Zhang, S.Y. and Zhang, Z. (2020) Single-Cell RNA Sequencing of 13 Human Tissues Identifies Cell Types and Receptors for Human Coronaviruses. Biochemical and Biophysical Research Communications, 526, Article ID: 951913. https://doi.org/10.1101/2020.02.16.951913

[13] Wölfel, R., Corman, V.M., Guggemos, W., Seilmaier, M., Zange, S., Müller, M.A., et al. (2020) Virological Assessment of Hospitalized Patients with COVID-2019. Nature, 581, 465-469. https://doi.org/10.1038/s41586-020-2196-X

[14] Yao, X.H., Li, T.Y., He, Z.C., Ping, Y.F., Liu, H.W., Mou, H.M., et al. (2020) A Pathological Report of Three Cases of COVID-19 by Minimally Invasive Autopsies. Chinese Journal of Pathology, 49, 411-417. https://doi.org/10.3760/cma.j.cn112151-20200312-00193

[15] Chen, Q., Quan, B., Li, X.N., Gao, G.J., Zheng, W.Q., Zhang, J., et al. (2020) A Report of Clinical Diagnosis and Treatment Report of Nine Cases of Coronavirus Disease 2019. Journal of Medical Virology, 92, 683-687.

https://doi.org/10.1002/jmv.25755

[16] Chan, J.F., Yuan, S.F., Kok, K.H., To, K.K.-W., Chu, H., Yang, J., et al. (2020) A Familial Cluster of Pneumonia Associated with the 2019 Novel Coronavirus Indicating Person-to-Person Transmission: A Study of a Family Cluster. Lancet, 395, 514-523. https://doi.org/10.1016/S0140-6736(20)30154-9

[17] Zhang, Z., Li, X.C., Zhang, W., Shi, Z.-L., Zheng, Z.S. and Wang, T. (2020) Clinical Features and Treatment of Patients with 2019-nCov Pneumonia in Wuhan: Report of a Couple Cases. Virologica Sinica, 35, 330-336. https://doi.org/10.1007/s12250-020-00203-8

[18] Lescure, F., Bouadma, L., Nguyen, D., Parisey, M., Wicky, P.-H., Behillil, S., et al. (2020) Clinical and Virological Data of the First Cases of COVID-19 in Europe: A Series of Cases. The Lancet Infectious Diseases, 20, 697-706. https://doi.org/10.1016/S1473-3099(20)30200-0

[19] Luo, C., Yao, L., Zhang, L., Yao, M.C., Chen, X.F., Wang, Q.L., et al. (2020) Possible Transmission of Severe Acute Respiratory Syndrome Coronavirus 2 (SARS-CoV-2) in a Public Bath in Huai'an, Province of Jiangsu, Chine. JAMA Network Open, 3, e204583. https://doi.org/10.1001/jamanetworkopen.2020.4583

[20] Yu, N., Li, W., Kang, Q.L., Xiong, Z., Wang, S.S., Lin, X.G., et al. (2020) Clinical Characteristics and Obstetric and Neonatal Outcomes of Pregnant Patients with COVID-19 in Wuhan, China: Single-Center Retrospective Descriptive Study. The Lancet Infectious Diseases, 20, 559-564. https://doi.org/10.1016/S1473-3099(20)30176-6

[21] Zeng, L.K., Xia, S.W., Yuan, W.H., Yan, K., Xiao, F.F., Shao, J.B. and Zhou, W.H. (2020) Early-Onset Neonatal SARS-CoV-2 Infection in 33 Newborns Born to Mothers with COVID-19 in Wuhan, China. JAMA Pediatrics, 174, 722-725. 
https://doi.org/10.1001/jamapediatrics.2020.0878

[22] Song, Y., Liu, P., Shi, X.L., Chu, Y.L., Zhang, J., Xia, J., et al. (2020) SARS-CoV2-Induced Diarrhea as an Onset Symptom in a Patient with COVID-19. Gut 2020, 69, 1143-1144. http://dx.doi.org/10.1136/gutjnl-2020-320891

[23] Young, B.E., Ong, S., Kalimuddin, S., Low, J.G., Yen, T.S., Loh, J., et al. (2020) Epidemiological Characteristics and Clinical Course of Patients Infected with SARS-CoV-2 at Singapore. JAMA, 323, 1488-1494. https://doi.org/10.1001/jama.2020.3204

[24] Hosoda, T., Sakamoto, M., Okabe, N. and Shimizu, H. (2020) SARS-CoV-2 Enterocolitis with Persistent Shedding of Virus for about Two Weeks after Recovery from Diarrhea: A Case Report. Infection Control \& Hospital Epidemiology, 41, 753-754. https://doi.org/10.1017/ice.2020.87

[25] Wang, D., Hu, B., Hu, C., Zhu, F.F., Liu, X., Zhang, J., et al. (2020) Clinical Characteristics of 138 Hospitalized Patients with Pneumonia Infected with the Novel Coronavirus 2019 at Wuhan, China. JAMA, 323, 1061-1069.

https://doi.org/10.1001/jama.2020.1585 